\title{
Pemberdayaan Masyarakat dan Mahasiswa dalam Pembersihan Pantai Pulau Kabung Selatan
}

\author{
Anthoni B Aritonang1, Shifa Helena2, Dwi Imam Prayitno², \\ Nora Idiawati2, Sy. Irwan Nurdiansyah2, Risko² \\ 1 J urusan K imia Fakultas M IPA U niversitas Tanjungpura Pontianak, \\ 2 Jurusan IImu Kelautan Fakultas M IPA U niversitas Tanjungpura, Pontianak \\ Korespondensi: shifahelena@ fmipa.untan.ac.id
}

\begin{abstract}
Kabung Island, which is located in the Bengkayang Regency Government area, is one of 226 small islands in West Kalimantan. Busy visits to the island during the school holidays and weekends have resulted in a large distribution of garbage in the waters and coasts of the island, and if it is not addressed promptly, it can cause global water problems. The Lecturer Team of the Department of Marine Affairs at the University of Tanjungpura as the implementation team of PKM activities to clean the beaches of Kabung Island, together with all the islanders and students of the Department of Marine Affairs, dive in cleaning the beaches and waters close to residential areas, sorting and collecting garbage, then burning and stockpiling it so that it does not get worse. accumulate and more and more enter the water bodies and can reduce the quality of the waters on the island. As many as 25 students were directly involved in the activity, and 20 residents from the island were directly involved in beach cleaning activities. From this activity, which is centered on the island of South Kabung, $100 \mathrm{~kg}$ of garbage has been collected consisting of plastic materials in the form of used drink bottles, styrofoam, diapers, and some trash carried from the middle of the sea, which may be carried away from the mainland coast. This activity is very necessary and is expected to continue as an annual routine activity of the Department of Marine Affairs, as a participation in preserving the sea and maintaining good water quality so that the diversity of species and population of a marine biota is not affected by the presence of these wastes.
\end{abstract}

Keywords: kabung: global; garbage; marine life; water quality

\begin{abstract}
Abstrak
Pulau Kabung yang berada dalam wilayah Pemerintahan Kabupaten Bengkayang merupakan salah satu dari 226 pulau kecil yang berada di Kalimantan Barat. Kunjungan yang ramai ke pulau tersebut pada musim liburan sekolah dan weekend, menyebabkan banyaknya sebaran sampah yang terdapat di perairan dan pesisir pulau tersebut, dan jika tidak diatasi dengan segera dapat menimbulkan masalah perairan secara global. Tim Dosen Jurusan Kelautan Universitas Tanjungpura sebagai tim pelaksana kegiatan PKM pembersihan pantai pulau Kabung, bersama dengan segenap masyarakat pulau tersebut dan mahasiswa Jurusan Kelautan, terjun membersihkan pantai dan perairan yang dekat dengan permukiman penduduk, memilah dan mengumpulkan sampah, kemudian membakar dan menimbunnya agar tidak semakin menumpuk dan semakin banyak yang masuk dalam badan perairan dan dapat menurunkan kualitas perairan di pulau tesebut. Sebanyak 25 orang mahasiswa terjun langsung dalam kegiatan dan 20 warga masyarakat dari pulau tersebut terlibat langsung dalam kegiatan pembersihan pantai. Dari kegiatan tersebut, yang dipusatkan pulau Kabung Selatan, terkumpul sampah sebesar $100 \mathrm{~kg}$ yang terdiri atas bahan plastik berupa botol bekas minuman, styrofoam, popok, dan beberapa sampah bawaan dari tengah laut, yang mungkin terbawa arus dari pesisir daratan.
\end{abstract}


Kegiatan ini sangat perlu dan diharapkan berlanjut sebagai kegiatan rutin tahunan dari Jurusan Kelautan, sebagai peran serta dalam melestarikan laut dan menjaga kualitas perairan tetap baik sehingga keanekaragaman jenis dan populasi suatu biota laut tidak terpengaruh oleh keberadaan sampah-sampah tersebut.

Kata kunci: kabung; pembersihan pantai, sampah; biota laut; kualitas perairan

\section{Pendahuluan}

Pesisir wilayah Indonesia sangat luas dengan garis pantai sepanjang $81.000 \mathrm{~km}$, yang mengandung kekayaan sumber daya alam yang sangat besar. Kalimantan Barat memiliki garis pantai sepanjang $2.453 \mathrm{~km}$ dan 226 pulau kecil. Pulau Kabung sebagai salah satu gugusan kepulauan yang termasuk ke dalam wilayah Kabupaten Bengkayang, merupakan sentra produksi ikan asin teri terbesar di Kalimantan Barat. Tidak heran jika kita memasuki perairan pulau tersebut, disambut dengan jajaran rumpun teri di sisi kiri kanan jajur transportasi laut antar pulau-pulau di wilayah tersebut. Pulau yang mata pencaharian penduduknya melaut dan berkebun tersebut terdiri atas 5 RT dengan pusat pemerintahan desanya di wilayah daratan, Desa Karimunting. Terdata sebanyak $300 \mathrm{KK}$ warga masyarakat mendiami pulau tersebut, yang terdiri atas multietnis, yakni Bugis Makassar dan Melayu, dengan penghidupan keluarga nelayan tersebut berasal dari hasil tangkapan ikan secara tradisional.

Selain sebagai sentra perikanan teri, Pulau Kabung juga menjadi tempat tujuan wisata, baik lokal maupun domestik, dan mancanegara, baik yang datang secara individu/ backpacking maupun dengan rombongan tur. Kabung menjadi destinasi wisata untuk tujuan olahraga snorkeling dan memancing yang wilayah pemancingannya berada di sekeliling pulau tersebut. Selain itu, Pulau Kabung juga menjadi lokasi riset oleh beberapa perguruan tinggi yang ada di Kalimantan Barat. Hal ini menyebabkan kunjungan ke lokasi tersebut tidak pernah sepi, terutama saat akhir pekan dan liburan sekolah. Kunjungan ke Pulau Kabung berkurang saat musim hujan dan gelombang tinggi.

Ramainya kunjungan wisatawan ke Pulau Kabung dengan berbagai tujuan tersebut tentunya sangat berefek pada lingkungan permukiman warga setempat, yang beberapa di antaranya digunakan sebagai rumah tinggal homestay bagi pengunjung dengan kualitas dan tarif yang beragam. Sampah yang bertebaran di daerah pemukiman wisatawan dan masih termasuk daerah pasang surut di pulau tersebut, akan masuk ke badan perairan dan terbawa arus sehingga bisa terdampar ke mana saja di sepanjang pulau tersebut. Pembiaran yang dilakukan, tentu saja, akan menyebabkan akumulasi jumlah dan jenis sampah dari tahun ke tahun sehingga pada akhirnya keberadaan sampahsampah tersebut akan berpengaruh terhadap kualitas perairan sekitar Pulau Kabung. Menurunnya kualitas perairan akan signifikan menurunkan keragaman dan jumlah populasi biota laut yang ada selama ini.

Beberapa penelitian terkait sampah perairan di antaranya adalah penelitian yang telah dilakukan oleh Handaka et al. (2007) di wilayah pantai selatan Kabupaten Garut melaporkan bahwa sampah yang ditemukan di pesisir tersebut sebanyak $65 \%$ merupakan hasil aktivitas dari wisatawan. Dari kuisioner yang diedarkan kepada masyarakat dan wisatawan sebagai responden, dilaporkan bahwa sebanyak $80 \%$ di antaranya menyatakan kondisi pantai tidak bersih. Meskipun demikian, angket tentang persepsi masyarakat 
di pesisir tersebut menunjukkan kepedulian yang cukup tinggi terhadap kebersihan perairan. Melaporkan bahwa permasalahan pencemaran perairan dan lingkungan pantai akan berefek terhadap kualitas perairan di sekitarnya dan pada akhirnya akan berdampak kuat pada kerusakan organisme perairan dan pesisir di sekitarnya. Terdapat hubungan dalam jaring-jaring makanan bagia biota perairan, seperti contoh sampah atau jenis cemaran lainnya dapat menurunkan kualitas perairan dan akhirnya menjadi racun bagi fitoplankton, selanjutnya fitoplankton akan menjadi makanan biota laut di tingkat yang lebih tinggi seperti ikan dan kerang-kerangan (Hutabarat dan Evans, 1985). Bahan cemaran lain seperti minyak dan batubara tumpah, logam berat hasil aktivitas manusia di daratan, pestisida sebagai limbah pertanian tidak dapat diabaikan keberadaan dan kelimpahannya dalam badan perairan karena jika tidak diantisipasi dengan segera akan menjadi permasalahan global di seluruh kawasan pesisir dan perairan seluruh Indonesia.

Pulau Kabung di Kalimantan Barat saat ini terus berkembang menjadi tempat wisata dan mulai dilirik banyak investor untuk pemanfaatan ekowisata. Dibukanya pulau Kabung untuk destinasi wisata membuat banyak wisatawan yang datang berkunjung ke pulau ini. Sayangnya, fasilitas tempat sampah yang disediakan warga setempat belum cukup menampung sampah oleh wisatawan, terutama saat akhir pekan dan musim liburan. Hal ini yang menyebabkan banyaknya sampah yang ditemukan di sepanjang pesisir Pulau Kabung. Sampah yang berada di tepi pantai ini tentunya sangat mengganggu estetika pantai serta dampak buruknya akan mengganggu ekosistem dan biota yang ada di Pulau Kabung. Selain itu, masih rendahnya kesadaran masyarakat akan sampah berdampak buruk untuk ekositem laut masih perlu terus disosialisasikan. Sosialisasi dampak sampah terhadap laut yang menjadi dasar kegiatan PKM ini, dengan bersamasama melakukan pembersihan pantai akan membantu menyadarkan masyarakat bahwa betapa banyak sampah di pesisir Pulau Kabung. Masyakat yang terlibat adalah beberapa stakeholder dan masyarakat setempat serta dosen-dosen dan mahasiswa-mahasiswi Jurusan Ilmu Kelautan Universitas Tanjungpura. PKM ini telah dilaksanakan pada 29 April 2019. Dengan adanya kebersamaan masyarakat, tim dosen dan mahasiswa Jurusan Ilmu Kelautan dalam membersihkan pantai dan perairan Pulau Kabung. Mereka dapat mengolah dan mengklasifikasikan jenis sampah buangan yang ditemukan di pesisir. Hal itu akan menjadi kegiatan yang sangat positif dalam meningkatkan kesadaran masyarakat untuk menjaga kebersihan perairan dan pesisir.

\section{Pendekatan Pelaksanaan Program}

Kegiatan PKM ini dilakukan dalam beberapa tahapan mulai dari persiapan sampai evaluasi dengan rincian tahapan, antara lain sebagai berikut.

- Survei lokasi ke pulau Kabung untuk menentukan kelayakan kegiatan di pulau tersebut, selanjutnya koordinasi dengan masyarakat setempat dan ketua-ketua RT dalam merencanakan kegiatan pembersihan pantai dan perairan Pulau Kabung, termasuk teknik dan jadwal pelaksanaan.

- Pengurusan perizinan ke pemerintah desa setempat dan penyampaian undangan kepada tokoh-tokoh masyarakat untuk hadir dalam kegiatan yang dimaksud.

- Persiapan peralatan dan bahan kegiatan seperti kantung-kantung sampah dalam berbagai ukuran, kaus tangan lateks, tong-tong sampah untuk pembakaran, dan 
tongkat-tongkat pengait sampah.

- Pelaksanaan kegiatan, dilaksanakan pada 24 April 2019 di pesisir pantai Pulau Kabung, yang dimulai dengan ceramah edukasi tentang kebersihan dan kesehatan laut, yang dilanjutkan dengan pendekatan secara fisik dalam artian terjun langsung mengajak bersama masyarakat dan mahasiswa mengambil dan mengumpulkan sampah yang berserakan di pantai dan perairannya.

- Kegiatan mengajak membersihkan pantai dengan metode memberikan contoh serta terjun langsung ke lapangan membuktikan efektif dalam kegiatan ini.

- Respons masyarakat terhadap kegiatan ini sangat antusias dan semangat memungut sampah. Meski cuaca terik, mereka tertawa dan bernyanyi agar tidak lelah saat membersihan pantai.

- Selanjutnya sampah diklasifikasi berdasarkan jenisnya dan selanjutnya untuk beberapa bahan yang sama dikumpulkan dalam wadah yang sama untuk dibakar dalam tong sampah berbahan drum besar bekas minyak.

- Kegiatan diakhiri dengan angket tentang pentingnya menjaga kesehatan laut, selain bisa menjadi daya tarik pengunjung karena keindahan dan kebersihan pulau, sekaligus juga menghindari terjadi penurunan kualitas air yang berefek pada berkurangnya keragaman dan populasi biota laut.

\section{Pelaksanaan Program}

Salah satu permasalahan nasional yang sangat pelik penanganannya adalah sampah karena terkait dengan perilaku manusia dan beberapa faktor lingkungan yang mendukung terjadinya penumpukan sampah sehingga pada akhirnya mengalami kesulitan dalam pengelolaannya. Untuk itu, sangat diperlukan adanya koordinasi dalam penanganan masalah sampah, terintegrasi antara pemerintah daerah dengan pelaku industri dan masyarakat, dan dilaksanakan secara komprehensif, terpadu dan berkesinambungan dari hulu ke muara sehingga dapat memberikan manfaat kesehatan dan kebaikan, keamanan, serta sikap serta perilaku masyarakat yang lebih peduli pada lingkungan sekitarnya.

Sampah di wilayah pesisir pantai dan perairan merupakan satu masalah yang sangat erat kaitannya dengan kebersihan lingkungan pesisir dan kesehatan perairan laut. Permasalahan yang ditemui di wilayah pesisir pantai umumnya adalah masih menumpuknya sampah hasil aktivitas rumah tangga dan bersebaran di pesisir pantai serta kurangnya kepedulian masyarakat sekitar pesisir terhadap kebersihan lingkungan pantai dan perairannya.

Pulau Kabung sebagai daerah destinasi bagi wisatawan lokal ataupun domestik dan beberapa kali ditemukan adanya wisatawan mancanegara, tak lepas dari masalah sampah. Pada umumnya, kunjungan ke pulau ini adalah untuk tujuan memancing ikan dan snorkeling di daerah terumbu karang yang tidak jauh dari bibir pantai. Rumah-rumah tinggal penduduk umumnya dibangun di atas daerah pasang surut. Saat air pasang, tiang rumah terendam $1-2$ meter, sedangkan pada saat surut, ketinggian air hanya mencapai pergelangan kaki. Rumah-rumah penduduk dalam masa-masa liburan dan terjadi lonjakan pengunjung ke pulau, umumnya dijadikan rumah sewa buat pengunjung. Kondisi rumah yang berada di bibir pantai memudahkan membuang sampah ke perairan secara langsung sehingga lama-kelamaan jika tidak diatasi akan terjadi akumulasi sampah 


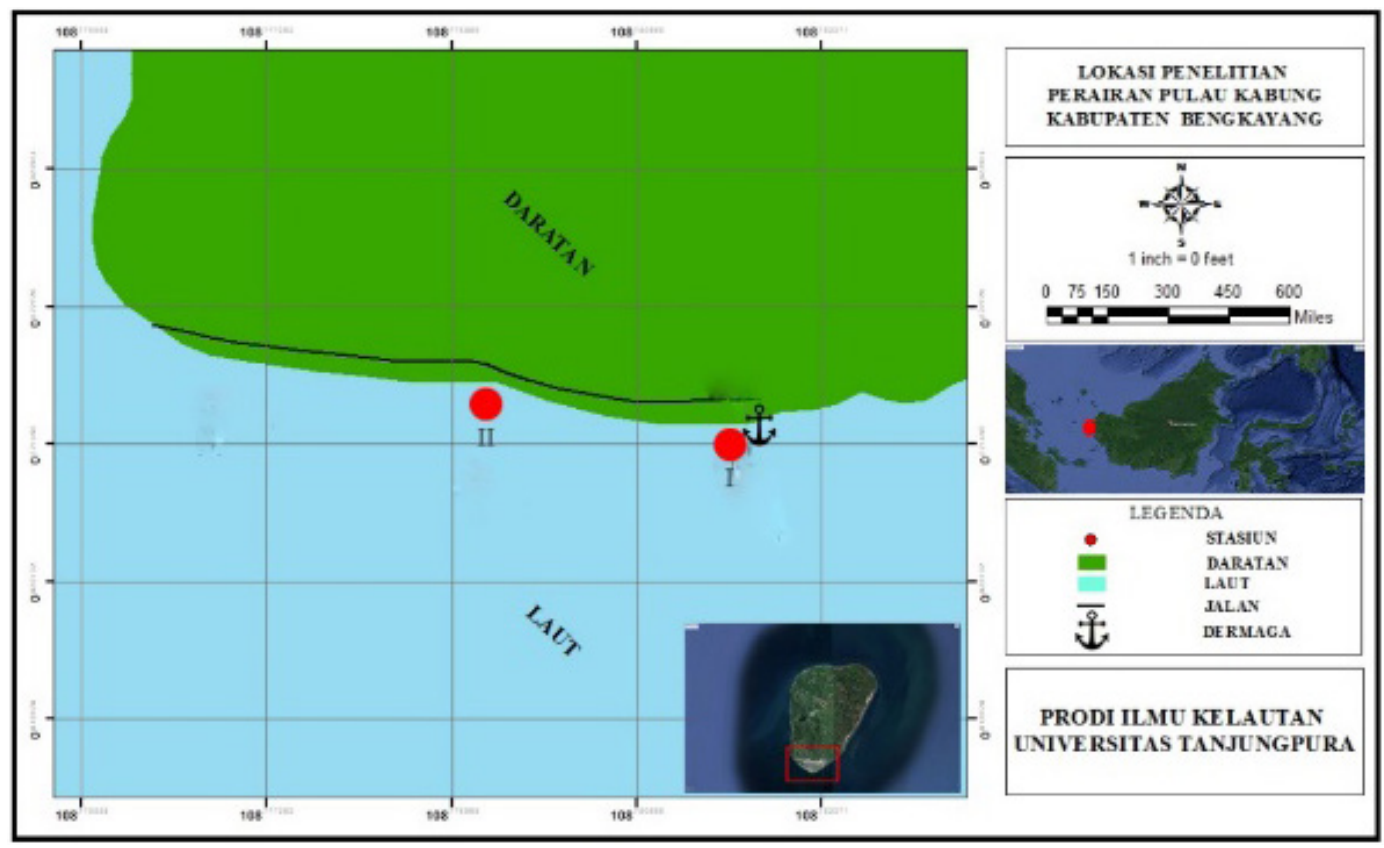

Gambar 1. Peta Lokasi Pulau Kabung.

dan berpengaruh terhadap kebersihan lingkungan pantai serta kesehatan perairan. Banyaknya sampah akan menjadi pemicu keracunan bagi fitoplankton dan makhluk renik lainnya, meski di sisi lain fitoplankton tersebut merupakan makanan bagi biota laut di tingkat atasnya.

Dalam kegiatan PKM ini, dilakukan dalam dua tahapan, yaitu pemberian ceramah edukasi tentang sampah, klasifikasi, dan pengolahannya yang dilanjutkan dengan pengaturan kelompok dan barisan serta lokasi pantai yang akan dibersihkan untuk masing-masing kelompok sebelum berpencar ke lokasi masing-masing. Menurut (Sohag et al., 2020), edukasi yang diberikan harus terkait sumber-sumber pencemaran sampah yang ada di pesisir serta solusi yang tepat dalam penanganannya. Pengelolaan limbah yang tepat harus menjadi prioritas untuk mengurangi pencemaran lingkungan dan untuk menjamin keselamatan kesehatan masyarakat. Di negara berkembang, pengelolaan dan kesadaran sampah merupakan konsep yang sedang berkembang. Untuk memastikan lingkungan yang sehat dan pembangunan berkelanjutan, pengelolaan limbah yang tepat adalah suatu keharusan.

Salah satu penyelesaian terbaik dalam menangani masalah sampah ini adalah menumbuhkembangkan komunitas masyarakat dengan segala bentuk kepedulian pada lingkungannya, terampil dan andal menyikapi usaha pencegahan pencemaran tersebut serta mengembangkan masyarakat untuk memiliki orientasi daur ulang sampah (Salim dan Febrinaldy, 2018). Selain itu, edukasi ini menekankan pada ajakan ke seluruh lapisan masyarakat di pesisir agar menjaga kebersihan pantai secara terus-menerus, dengan menyampaikan beberapa risiko yang dapat mengancam kelangsungan hidup biota perairan laut jika dilakukan pembiaran. Sampah yang tidak tertangani dengan tepat dan baik akan menjadi pemicu tingginya toksisitas perairan terhadap plankton dan 

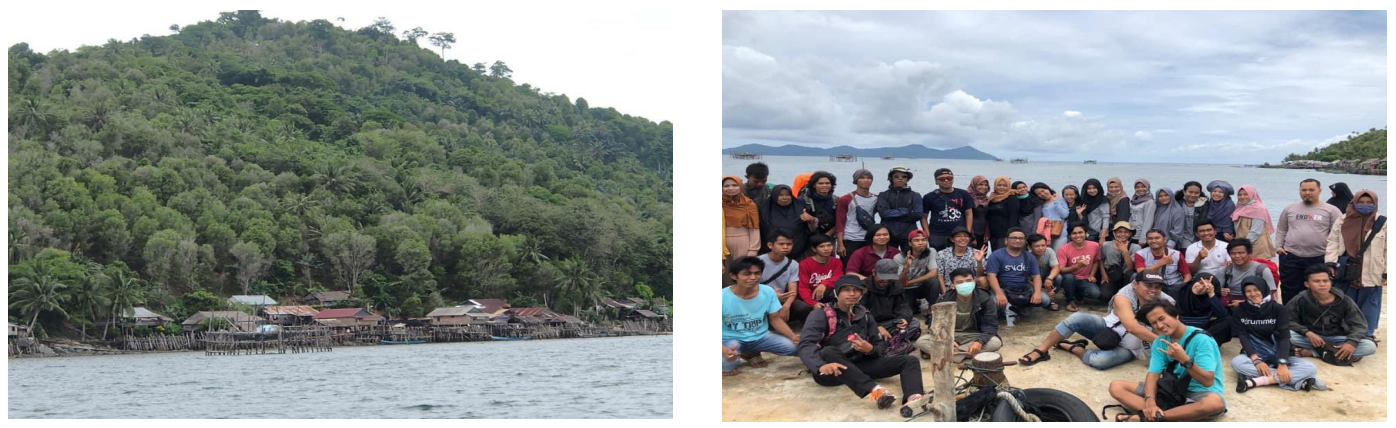

Gambar 2. Pulau Kabung dari kejauhan (kiri) dan berkumpul sebelum kegiatan pembersihan Pantai (kanan)
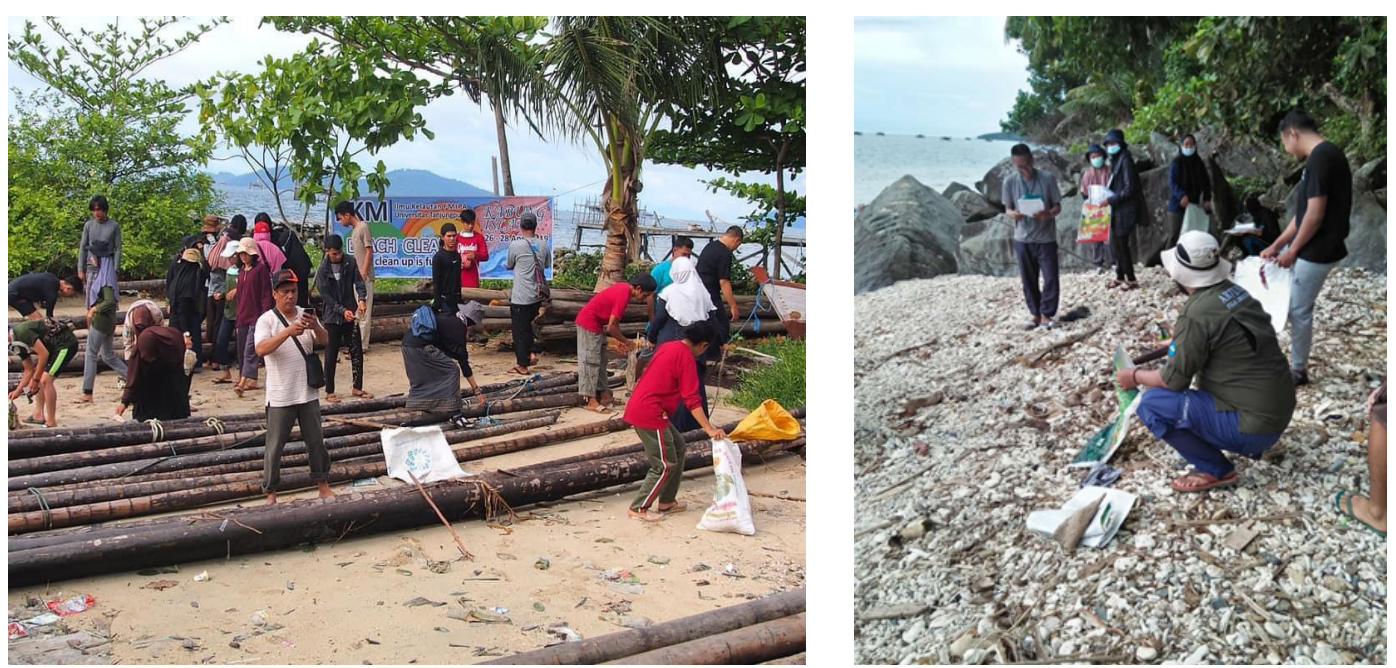

Gambar 3. Pemungutan sampah dan penyortiran sekaligus pencatatan bobot sampah

berpengaruh secara fisika, kimiawi, dan biologis terhadap kualitas perairan (Zainuddin dan Salim, 2018). Sistem rantai makanan akan terganggu jika salah satu komponennya mengalami gangguan. Jika ini terjadi, perairan akan berada pada kondisi kritis untuk kehidupan biota laut seperti ikan dan kekerangan, yang pada akhirnya aktivitas memancing sebagai tujuan wisata ke pulau tersebut akan sepi pengunjung.

Beberapa hal yang perlu mendapatkan perhatian dalam kegiatan pembersihan langsung ke pantai dan perairan di Pulau Kabung ini antara lain adalah sebagai berikut.

1. Sampah-sampah dari 5 titik lokasi pembersihan di bagian Selatan Pulau Kabung dikumpulkan dalam satu lokasi, kemudian disortir antara sampah yang bisa didaur ulang seperti kertas, pecahan plastik, dan pecahan kaca.

2. Memisahkan sampah yang kotor dan berbahaya, seperti pamper, pembalut, untaian jaring dari tali nilon, dan stereofom agar jauh dari jangkauan terutama anak-anak.

3. Sampah yang sudah disortir selanjutnya ditimbang. Sampah yang kotor dan berbahaya dapat dibakar saat sudah kering dalam tong sampah, sedangkan sampah yang bisa didaur ulang dapat disimpan untuk dijual kepada para pengepul barang bekas. 


\section{Refleksi Capaian Program}

Hasil pelaksanaan kegiatan PKM ini adalah terkumpulnya sampah sebanyak $80 \mathrm{~kg}$ yang terdiri atas $60 \mathrm{~kg}$ sampah daur ulang seperti pecahan plastik, kaca, besi, dan sampah campuran kering serta basah yang siap untuk dibakar dalam tong sampah. Pada akhir kegiatan diberikan angket kepada masyarakat Pulau Kabung yang turut serta dalam pembersihan pantai dan hasilnya menunjukkan bahwa $83 \%$ dari 30 warga masyarakat yang menjadi responden sudah mengetahui tentang efek timbunan sampah di pantai dan perairan terhadap kualitas perairan dan biota lautnya. Selain itu, hanya 12 orang (40\%) warga yang menyatakan selalu menjaga kebersihan laut dan pantai dengan memungut setiap melihat sampah dan membawanya ke darat untuk dibakar. Seluruh responden menyampaikan keinginan perlunya tong-tong sampah yang besar dan bisa sekaligus dijadikan pembakaran sampah. Pengelolaan limbah yang buruk akan mengarah pada pencemaran lingkungan. Pembuangan terbuka dan pengambilan sampah di tempat pembuangan terbuka menyebabkan risiko kesehatan yang serius seperti infeksi kulit dan penyakit kronis (Silpa et al., 2018). Di daerah kumuh, situasinya menjadi lebih buruk karena kepadatan penduduk yang tinggi. Ini merupakan indikasi yang jelas bahwa masalah lingkungan/kesehatan dan pengelolaan sampah yang buruk saling terkait. Peningkatan populasi, urbanisasi, dan industrialisasi meningkatkan tingkat timbulan sampah di seluruh dunia. Lebih dari $64 \%$ populasi di negara berkembang dan lebih dari 84\% di negara maju (Abidin, 2015). Oleh karena itu, pengelolaan sampah merupakan isu global dalam hal berbagai dampak lingkungan dan sosial. Pengolahan sampah di Pulau Kabung harus menyediakan sistem pengelolaan sampah yang efektif agar tidak mencemari lingkungan dan menjamin keselamatan kesehatan masyarakat. Banyaknya jumlah pencemar di kawasan pantai sangat dikhawatirkan akan merusak tidak hanya ekosistem di sekitarnya, tetapi juga kualitas kesehatan warga pantai yang bersangkutan. Dengan demikian, sekali menjaga kebersihan pantai dan perairan Pulau Kabung, keselamatan hidup biota laut dan masyarakat di Pulau Kabung akan terjamin.

\section{Penutup}

Dari hasil pelaksanaan kegiatan PKM Pembersihan Pantai Pulau Kabung Bagian Selatan berbasis Pemberdayaan Masyarakat dapat disimpulkan sebagai berikut.

1. Masyarakat sudah memahami tentang pentingnya menjaga kesehatan dan kebersihan lingkungan pantai dan perairan dari segala macam sampah karena dapat memengaruhi kualitas perairan dan biota laut di dalamnya dengan angket semacam kuesioner singkat kepada masyarakat dan stakeholder setempat.

2. Masyarakat sudah dapat memahami pentingnya menyortir dan mengumpulkan sampah yang sejenis sebelum dibakar, dari sampah yang terkumpul pada kelima titik pembersihan pantai, diperoleh sampah seberat $80 \mathrm{~kg}$ yang terdiri atas $60 \mathrm{~kg}$ sampah daur ulang dan $20 \mathrm{~kg}$ sampah campuran yang siap bakar.

3. Adanya harapan yang besar dari seluruh warga masyarakat Pulau Kabung yang terlibat dalam kegiatan bersih pantai untuk melakukan kegiatan ini secara rutin dalam periode waktu tertentu, karena kesehatan dan kebersihan lingkungan dapat menjamin kesehatan dan keselamatan manusia dan biota laut. 
4. Rekomendasi yang perlu dilakukan adalah pembuatan tempat sampah yang banyak di lokasi Pulau Kabung, serta tempat sampah tadi sebaiknya disesuaikan dengan kategori sampah agar pengolahan limbah di Pulau Kabung bisa lebih maksimal.

\section{Daftar Pustaka}

K. Silpa dkk. (2018). What a waste 2.0: a global snapshot of solid waste management to 2050. Urban Development Series

M.A. Abedin. (2015). Waste generation and management in Bangladesh: An overview Asian J. Med. Biol. Res.

Minhaz Uddin Sohag., Amit KumerPodde. (2020). Smart garbage management system for a sustainable urban life: An IoT based application. https://doi.org/10.1016/j. iot.2020.100255

Salim, G dan Febrinaldy R. (2018). Introduksi dan Penerapan Sistem Program Coastal Clean-Up. Jurnal Pengabdian Masyarakat Borneo (JPMB). Universitas Borneo Tarakan. Volume 2 Nomer 1. Halaman 39-43. (E-ISSN:2579-9797 dan P-ISSN: 2615-4323) http://jurnal.borneo.ac.id/index.php/jpmb/index

Zainuddin dan Salim. (2018). pengenalan coastal cleanup di kawasan ekowisata Pulau Derawan Kabupaten Berau Kalimantan Timur. Jurnal pengabdian masyarakat Borneo (JPMB) Volume 2 nomor 2 Desember 2018 (E-ISSN:2579-9797 dan P-ISSN: 2615-4323) e-journal : http://jurnal.borneo.ac.id/index.php/jpmb/ 